\title{
The Myth of an 'Invisible Mediator': An Australian Case Study of English-Japanese Police Interpreting
}

\author{
Ikuko Nakane, University of Melbourne
}

\section{Introduction: Interpreter roles in legal contexts}

This article explores the roles and management of discourse by police interpreters. The traditional view of the legal interpreter as a 'conduit' (Russell 2000: 36-37; Laster \& Taylor 1994: 112; Yoshida 2007: 20) suggests that interpreting processes are not relevant as evidence in court. It has also been suggested that people who use interpreters tend to expect them to be invisible (Laster \& Taylor 1994; Wadensjö 1998; Roy 2000; Leung \& Gibbons 2008). Thus, while police records of interviews are important evidence in court, when interviews are mediated by an interpreter there are few traces of the interpreting process in the evidence that appears in court. Similarly, as has been demonstrated by existing studies (Berk-Seligson 1990; Eades 1996; Hale 2004), court transcripts do not show the ways in which aspects of interpreting processes may have had impacts on the outcomes of the cases.

The expectation that interpreters are, or should be, invisible is related to the professional code of ethics for interpreters. The Australian Institute of Interpreters and Translators (AUSIT) code of ethics obliges interpreters to interpret accurately, stating that they 'shall not alter, make additions to, or omit anything from their assigned work' (National Accreditation Authority for Translators and Interpreters 2001: 14). Furthermore, the code also states that interpreters should remain impartial: 'professional detachment is required for T\&I [Translation and Interpreting] assignments in all situations' (NAATI

PORTAL Journal of Multidisciplinary International Studies, vol. 6, no. 1, January 2009. 
2001: 13). In other words, interpreters should not let their personal opinions influence their performance.

However, it has been demonstrated that legal interpreters do play roles other than that of 'conduit,' while engaging in various types of discourse management (Angermayer 2005; Berk-Seligson 2002; Leung \& Gibbons 2008; Russell 2000, 2002; Wadensjö 1998). Such role shifts may affect the outcome of interactions between the police investigator and the interviewee (Berk-Seligson 2002; Russell 2000, 2002; Wadensjö 1998). The present study explores this issue of interpreter roles, through a focus on the problem-solving strategies of Japanese-English interpreters when mediating interviews conducted by the Australian Federal Police. This focus has been chosen because 'role shifts' become salient in the data set when problem solving is required or a problem is anticipated. Specifically, the article addresses four questions. First, can interpreters maintain their invisibility when a communication problem is perceived? Second, what roles do interpreters take in handling communication problems? Third, how and why do interpreters' role shifts occur? And fourth, what are the practical and theoretical implications of the interpreters' handling of problems?

\section{The study}

The data used for the study analysed in this essay are Australian Federal Police recordings of four interviews with suspects who were Japanese citizens. Three interviews come from a drug-smuggling case that took place in Melbourne. All the suspects in this case were found guilty and deported to Japan. ${ }^{1}$ The remaining interview in the data set is also from a drug case, but it took place in Sydney and the suspect was acquitted after a trial. Three of the interpreters (referred to as Interpreter 1, 2 and 4) were speakers of Japanese as a first language, and one, (Interpreter 3), was a speaker of English as a first language. Interpreter 1 had Professional Interpreter accreditation from the National Accreditation Authority for Translators and Interpreters (NAATI), ${ }^{2}$ and the other three interpreters had Paraprofessional Interpreter accreditation in JapaneseEnglish interpreting. It has been claimed that the minimum level of accreditation for

\footnotetext{
${ }^{1}$ One of the suspects is Chika Honda, whose story associated with this case was reported extensively in the media in Japan and Australia (Susuki 2000; Unde 2000; Hyland 2008).

${ }^{2}$ According to NAATI, Professional Interpreters 'are capable of interpreting across a wide range of subjects involving dialogues at specialist consultations,' while Paraprofessional Interpreters 'generally undertake the interpretation of non-specialist dialogues' (NAATI n.d.).
} 
legal interpreting should be Professional, even though this does not necessarily guarantee minimum quality due to the specialised nature of legal language (Laster \& Taylor 1994: 30; Hale 2004: 25-27). Thus, three of the interpreters in the present study could be said to lack sufficient qualifications for legal interpreting. However, the present study is concerned with what actually occurs in the legal process, not in ideal circumstances. Since interpreters with paraprofessional accreditation are given assignments by the police and the court in Australia, it is worthwhile exploring the discourse processes in this data set in order to determine what practical implications they have.

\section{Analytical framework}

The analysis in this article adopts a perspective of interpreters as one of the participants in a communicative event (Wadensjö 1998; Roy 2000; Russell 2000; Angelelli 2004; Nakane 2007; Yoshida 2007) rather than as an 'invisible' mediator. The analysis specifically draws on Goffman's (1981) notion of participation roles played by speakers that was adopted by Wadensjö (1998) in her study of interpreter roles. Goffman (1981: 226) says that a speaker can be an animator, one who has a role of 'the sounding box from which utterances come,' while an author is 'the agent who puts together, composes, or scripts the turns that are uttered.' Additionally, when a speaker takes the role of principal, they are 'the party to whose position, stand, and belief the words attest.' Thus, the 'default' interpreter role would be associated with that of animator, while the editing or modifying of the source text (or the primary speaker's utterance) would make the interpreter an author. Furthermore, at times some interpreters step out of their default 'conduit' or animator role and intervene as a principal, as their own selves, instead of speaking on behalf of the primary speakers. For example, when the interpreter says his/her own name for the record at the beginning of the police interview, they are taking the role of principal.

In identifying problems in interpreter-mediated discourse, the 'organization of repair' (Schegloff et al. 1977: 361) in the tradition of Conversation Analysis (CA) was examined. Recent studies in interpreting have demonstrated the benefit of a CA approach by revealing the active roles of the interpreter in co-constructing discourse with the primary speakers (Wadensjö 1998; Roy 2000; Petite 2005; Nakane 2007). Furthermore, CA focuses on speakers' orientation to the interaction (Sacks et al. 1974: 
699-700; Levinson 1983: 286-87). Therefore, an examination of repair sequences can reveal what the participants of police interviews perceived to be interactionally problematic, and how the interpreters handled such problems.

In this article I examine 'repair' in interpreter-mediated police interviews. Wong (2000: 247) defines repair as '[e]fforts to deal with any problems in speaking, hearing or understanding of the talk,' which includes 'confirmation checks, clarification requests, restatements, repetitions, understanding checks.' Repair occurs when the orderliness and coherence of conversation is at risk and, as a result, the participants in conversation deal with 'trouble sources' that may threaten intersubjectivity, or participants' shared assumptions, which enable mutual understanding about what goes on in interaction (Schegloff 1992: 1295-96). Repair can be categorised into 'self repair' and 'other repair,' depending on whether speakers are repairing their own speech or that of other participants. When self-repair is not done immediately by the speaker whose speech turn became the source of problem, it can take the following sequential structure (ten Have 1999: 116-17; Schegloff et al. 1977: 364):

Speaker A: Trouble source

Speaker B: Next turn repair initiator

Speaker A: Self repair

The following is an example from Schegloff et al. (1977: 368):

B: .hhh Well I'm working through the Amfat Corporation. (Trouble source)

A: The who? (Next turn repair initiator)

B: Amfah Corporation. T's a holding company. (Self repair)

According to Heydon (2005: 99), four-part repair sequences, as shown below, are commonly found in police interviews:

$\begin{array}{ll}\text { Police officer: } & \text { Question 1 (Trouble source) } \\ \text { Suspect: } & \text { Question 2 (Next turn repair initiator) } \\ \text { Police officer: } & \text { Answer 2 (Question 1 repaired) } \\ \text { Suspect: } & \text { Answer 1 }\end{array}$

This type of repair sequence was also found frequently in the data in the present study. However, in interpreter-mediated police interviews, the above sequence would have eight parts instead of four because of the interpreting of each turn. Moreover, because of the existence of two possible 'trouble source' turns (the source text and the interpreter's target text), the repair process sometimes becomes complicated. Below, I demonstrate how interpreter roles shift in various problem-solving situations in police interviews. 


\section{Interpreter roles and discourse management}

Interpreter as 'animator' in repair sequence

In the role of animator, the interpreter would speak completely on behalf of the primary speakers. This means that the interpreter would render the next-turn repair initiator (i.e. indication of need for repair by the 'trouble source' speaker), treating it as directed towards the speaker of the 'trouble source' and not towards him/herself. The following extract is an example of repair sequences rendered by the interpreter taking up a role of invisible mediator (for details of transcription conventions, see the appendix):

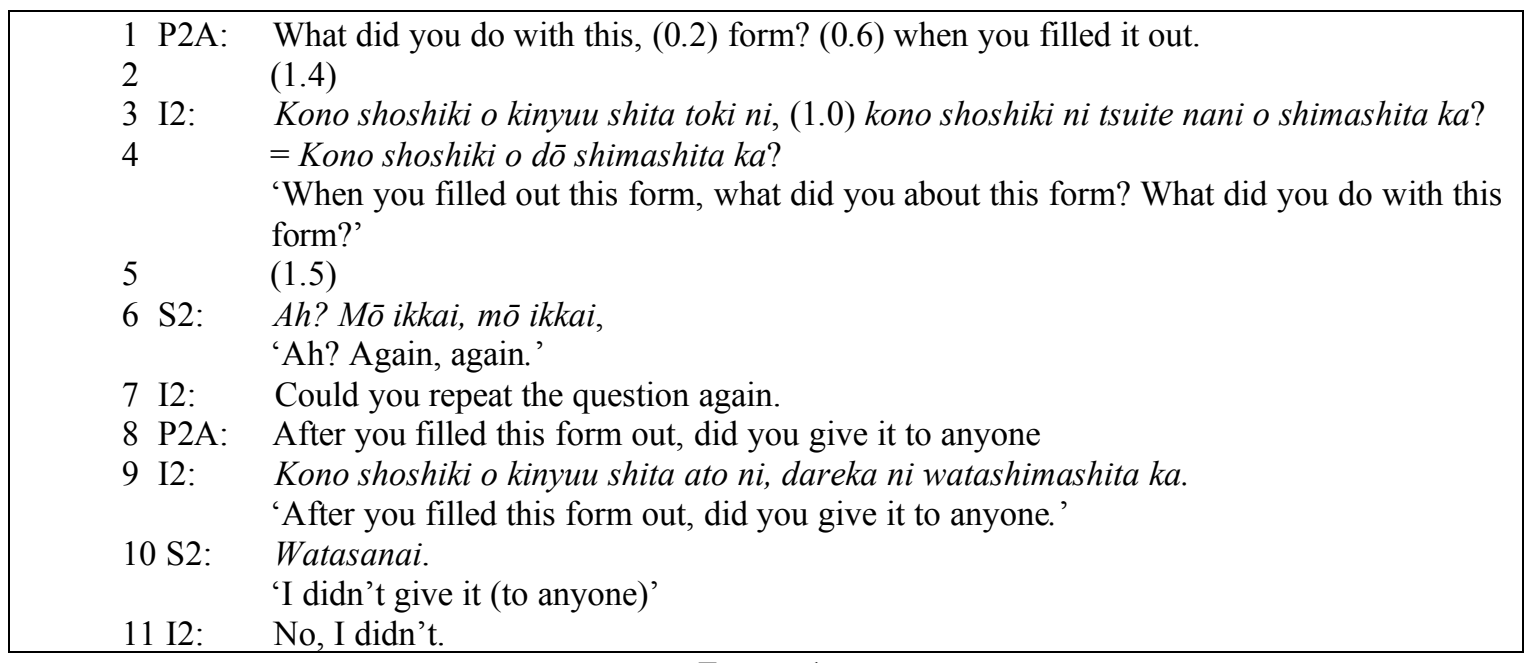
Extract 1.

Here, we see an example of a four-part repair sequence starting with the police officer's question. Although the interpreter quickly self-repairs in line 4 for a better translation of 'what did you do,' the suspect appears to find the question confusing, as he initiates a repair in line 6 after a pause. This repair initiator is rendered by the interpreter in line 7 , and the police officer repairs the rather vague question (line 1), modifying it to be more specific. Immediately the suspect responds to the interpreted repaired question in line 10, which is rendered as a coherent response in line 11 by the interpreter. The initial question was vague, as evidenced by the police officer's pauses, and the pause the interpreter allowed in line 2 despite the straightforward syntactic and semantic property of the source text. It is possible that the police officer was aware that the question was poorly phrased and made the question more specific despite the next turn repair initiator requesting a repetition rather than a specification. As far as the interpreter role is concerned, the animator role was maintained throughout this sequence. This is the 'default' role expected of legal interpreters who are expected to maintain impartiality and accuracy, as stipulated by the code of ethics. 


\section{Interpreter repair initiation as 'author' in 'off the record' repair}

Interpreters are sometimes described as mediators who help their clients to overcome not only linguistic barriers, but cultural barriers as well (Laster \& Taylor 1994: 119; Yoshida 2007: 21). The extent to which they function as a 'cultural bridge' is a sensitive issue, as accuracy should not be sacrificed. However, the interpreters are usually the only participants who have access to the two languages used in their assignments, and they can anticipate problems caused by using a direct equivalent in certain situations. Below is an example of a repair sequence in which the interpreter avoids a possible misunderstanding by quickly repairing 'off the record' to remove the risk:

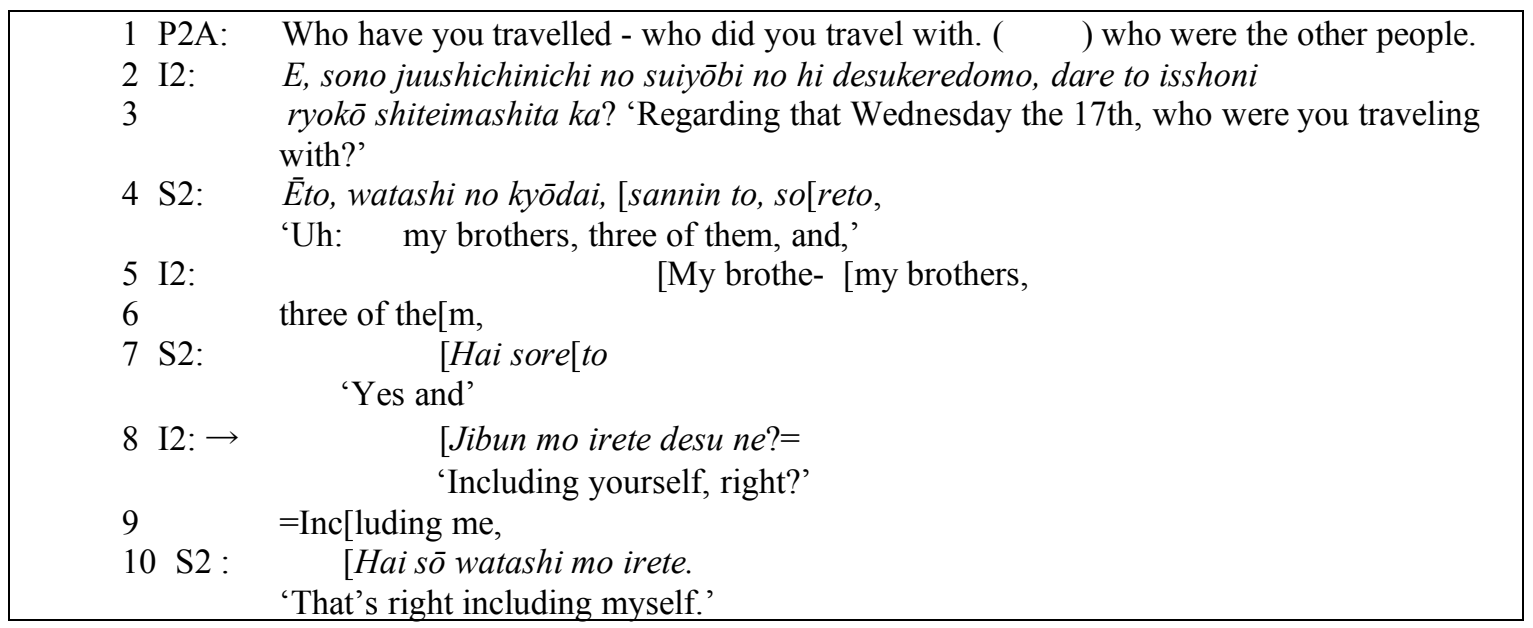

Extract 2.

In Japanese, when talking about the number of siblings it is common to hear, for example, literally 'We are three brothers,' including the speaker himself. Thus, through a direct translation between English and Japanese, there is a risk of understanding the number incorrectly. Being aware of this risk, after rendering a literal translation in lines 5-6, the interpreter interrupts the suspect in line 7, questioning whether the "three brothers' includes himself. Without waiting for the suspect's response to this question, the interpreter modifies the suspect's original reply in line 4 to avoid the risk of the police officer misunderstanding the number of brothers. The subsequent modification of the response to ensure accurate rendition of the original meaning suggests that the interpreter took the role of author, moving from a 'sounding box' towards a 'cultural bridge.' However, this role shift does not go against the code of ethics, as it also recommends to interpreters that they 'shall ask for repetition, rephrasing or explanation' if anything is unclear (NAATI 2001: 14). The repair effectively avoided potential 
miscommunication that only the interpreter could anticipate and ensured accurate rendition of the primary speaker's message.

\section{Moving between author and principal}

Although an 'off the record' repair initiation by the interpreter is necessary at times in order to avoid the pitfalls of seemingly straightforward translation causing cross-cultural misunderstanding, as shown above, there are examples of repairs initiated by the interpreters in their attempts to elicit a coherent or preferred response to the police officer's question. In such cases, they take the role of principal and become a coinvestigator. ${ }^{3}$ Below is one such example:

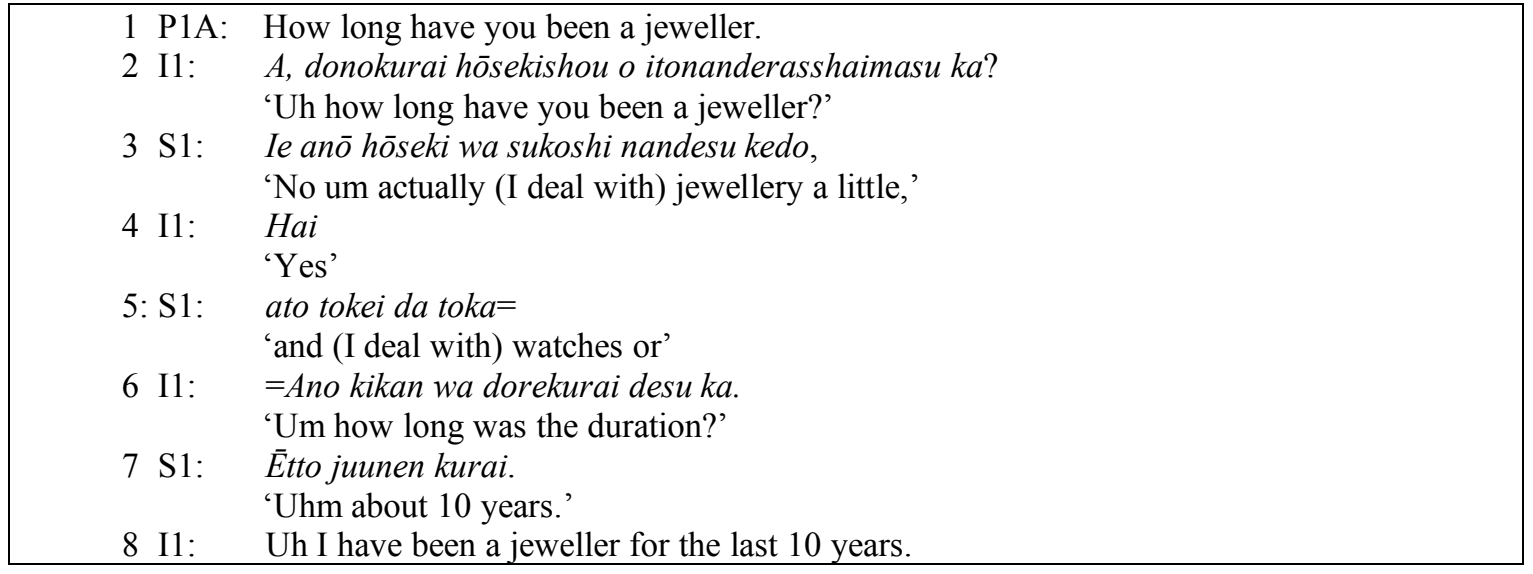
Extract 3.

In this example, the 'off the record' repair initiation strategy goes beyond an ethically acceptable level. In the unmarked role of animator, the interpreter would render the suspect's utterances in lines 3 and 5 in English. However, judging these utterances as irrelevant to the police officer's question, the interpreter reformulates her initial rendition (line 2) in line 6, as an interruption, latching onto the suspect's utterance in line 5. This reformulated turn is a next turn repair initiator, as she deems the suspect's turn problematic and specifically requests 'the duration.' The suspect repairs in line 7, allowing the interpreter to render a coherent response to the question posed in line 1. However, the information that S1 dealt with watches (and possibly other things) is lost here although it actually becomes relevant later on in the interview.

This is an example of problematic action by the interpreter, who seeks to avoid a threat to coherent interaction and attempts to elicit answers 'acceptable' to the police officers.

\footnotetext{
${ }^{3}$ The interpreter (I1) in this extract is the only interpreter in the data set with a NAATI Professional accreditation.
} 
By not rendering the information provided by the suspect and making him focus on the duration of time he worked as a jeweller, this interpreter is violating the code of ethics in terms of accuracy and impartiality. Nevertheless, it should be noted that the interpreter is still, to some extent, engaging in the task of interpreting, as she reformulates the initial question. (Examples in which the interpreter stops interpreting and starts talking as a third party are provided later in this article). The information that was not communicated to the interviewing police officer, however, could have had serious implications for the case. The suspect's business connections with an overseas contact person were probed by the police officer later in the interview. However, when the suspect mentioned a discussion about watches with this contact, the police officer may have drawn a negative inference from the suspect's testimony, as dealings involving watches had not been previously mentioned to him.

The extract below shows a similar case in which the interpreter, faced with a dispreferred response, reformulates in line 5 his first rendition (line 2) without rendering the suspect's initial response (line 4) for the police officer:

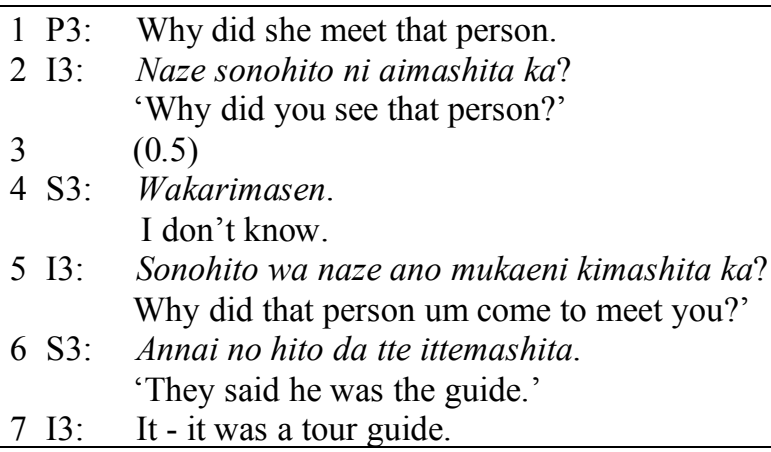

Extract 4 .

In the animator role, the interpreter would have rendered what was said in line 4. However, the pause in line 3, and the suspect's response 'I don't know' in line 4, may also indicate that the suspect was confused by the question. This is possible because 'aimasu (the past aimashita),' the equivalent of 'meet' in Japanese in line 2, with the 'why' interrogative, implies that the suspect had arranged to meet 'that person.' Noticing the confusion, and possibly being aware that the suspect's response in line 4 may suggest his own incompetence, the interpreter self repairs in line 5 by replacing the term ' $a u$ ' (to meet) in line 2 with the term 'mukaeru' (to come and meet). This functions as a next turn repair initiator, which successfully (from the interpreter's point of view) elicits a repaired response. However, had the suspect's response 'I don't know' been 
rendered in English, it may have indicated that, if she had not arranged to meet 'that person,' the police officer's question did not make sense to her. Furthermore, the omission of 'They said' in the rendition in line 7 makes her responsible for the knowledge that 'that person' was a tour guide. In other words, the omission projects her as an insider who knew that the person who met her tour group was a tour guide, rather than a peripheral member of the tour group who only heard from other members of the group that this person was a tour guide.

Thus, although the interpreter does seem to be engaging in interpreting as an author, by avoiding renditions of what he deems irrelevant and of problems associated with interpreting itself, his role leans towards that of principal, as in the previous example. It should be noted that the interpreter in this excerpt has Japanese as his second language, which may explain his correcting himself without rendering the suspect's initial response. In other words, he may have felt insecure about his rendition of the police officer's question into Japanese. ${ }^{4}$

These examples of role shifts may occur either because the interpreter feels (inappropriately) responsible for not eliciting preferred or relevant responses from the suspect or because the interpreter is unsure of the quality and accuracy of their first rendition. In the former case (extract 3), at least in Australia, the behaviour of Interpreter 1 breaches the code of ethics because she fails to render the suspect's response (accuracy) and allows her personal judgement of relevance influence her performance (impartiality). In the latter case (extract 4), the interpreter tries to ensure the quality and accuracy of his rendition, while protecting his reputation - that of a competent interpreter - at the cost of denying the police officer access to the information provided by the suspect. Unlike the former example, in the latter, the lack of rendition of the first response 'I don't know' may have favoured the suspect in that a refusal to give information would make the police suspicious (Kurzon 1995: 68). Thus it appears that role shifts may variously favour or disadvantage suspects, depending on the information that is lost or repaired through the interpreters' discourse management.

The interpreter's vulnerability and need to protect their reputation as a competent interpreter (Jacobsen 2008: 154) may also be evoked by requests for clarification by the

\footnotetext{
${ }^{4}$ A comparison of interpreters with different first language backgrounds may bring some interesting insights but it is beyond the scope of this paper.
} 
primary speakers. In theory, if the interpreter follows the code of practice, rendering completely and accurately what is said (accuracy) without responding to it of their own accord (impartiality) as animator, they are expected to faithfully render a request for clarification (i.e. 'repair initiator') by the primary speakers. An example of this was given in extract 1 above.

In the next two extracts, however, the interpreters repair the 'trouble source' without rendering the clarification question from the police officer. The extract below shows an example where the interpreter directly responds in English (line 7) to the police officer's confirmation request regarding the nationality of a driver involved in the case (line 6).
1 P3: What nationality was he?
2 I3: Untenshusan wa nanijin deshita ka?
'What nationality was the driver?'
$3 \quad(0.5)$
4 S3: Eto: (0.4) Nihonjin ja nai desu.
'Uhm He wasn't Japanese.'
5 I3: He wasn't Japanese,
6 P3: He wasn't Japanese?
7 I3: He wasn't Japanese.

Extract 5 .

In an animator role, the interpreter would be expected to render the repair initiation in line 6 into Japanese, assuming that the question was directed to the suspect. If the nationality of the driver became a contentious issue in the investigation or in the evidence, then the fact that the interpreter, not the suspect, had confirmed that the driver wasn't Japanese, become a problem in terms of legal processes.

Below, is another example of a repair initiation by the police officer. Instead of rendering the police officer's question in line 5, the interpreter repairs her own rendition (line 4) of the suspect's response (line 3) in English, directly responding to the request for clarification. She makes three changes: the order of the clauses, the replacement of
1 P4A: How were you going to travel from the airport to the hotel.
2 I4: De kuukō kara hoteru made wa donoyōni iku yotei deshita ka. 'And how did you plan to travel from the airport to the hotel?'
3 S4: $\quad$ Mada nanimo kangaetenai toki ni kore de heh heh kore dattande heh heh 'Because this happened when I hadn't thought about any plans.'
4 I4: Ah hah before I think about that I was already arrested. U:hm
5 P4A: What, sorry,
6 I4: I - I was already suspended,
7 P4A: Right,
8 I4: The - before I think about how to get there.
9 P4A: Okay. 
'arrested' with 'suspended' and specifying the pronoun 'that' in 'think about that.' The police officer accepts this clarification in line 9. It cannot be verified from the audio recording, but the suspect in line 3 is probably referring to his arrest when he says 'kore dattande' (it was this), by using a gesture that indicates being arrested.

In both examples above, the fact that the request for repair in English is not rendered into Japanese for the suspect suggests that interpreters may treat a repair request as directed to themselves as interpreters - or principals - rather than to the suspects. Strictly speaking, this lack of rendition, and direct response, is not acceptable, because the source utterance was not rendered (accuracy) and the interpreter answered the question (impartiality).

However, in terms of interactional mechanisms, it is not an unreasonable reaction. In interpreter-mediated discourse, the number of 'trouble source' turns in repair sequences is doubled - one is produced by the primary speaker and another produced as the translated version by the interpreter. In such situations, the interpreter becomes vulnerable, especially since their turn occurs immediately before the request for repair. Thus, even if the problem derives from the primary speaker's original utterance and not the interpreter's rendition turn, and since it is in our nature to attend to the immediately preceding turn in our everyday interaction (Sacks et al. 1974: 708; Levinson 1983: 339), the interpreter may find it difficult to maintain an animator role, especially in the faceto-face consecutive mode of interpreting, as it is easy for the primary speaker to direct their gaze towards the interpreter who has just produced the immediately preceding turn. The ramifications of this type of repair could be a complex issue, however. If, for example as in excerpt 6 above, the interpreter renders the police officer's 'What, sorry?' faithfully, then the initial response from the suspect will be lost to the police officer and it is possible that the suspect may give different information as a repaired version. It may also be the case that the police officer was asking the interpreter to repeat the translation.

\section{Interpreter's repair initiation as a 'principal'}

In some instances, interpreters are responsible for their words and thus act as a principal, moving further away from their expected animator role. In one example, this happens when the police officers need to borrow the interpreter's knowledge about Japan: 


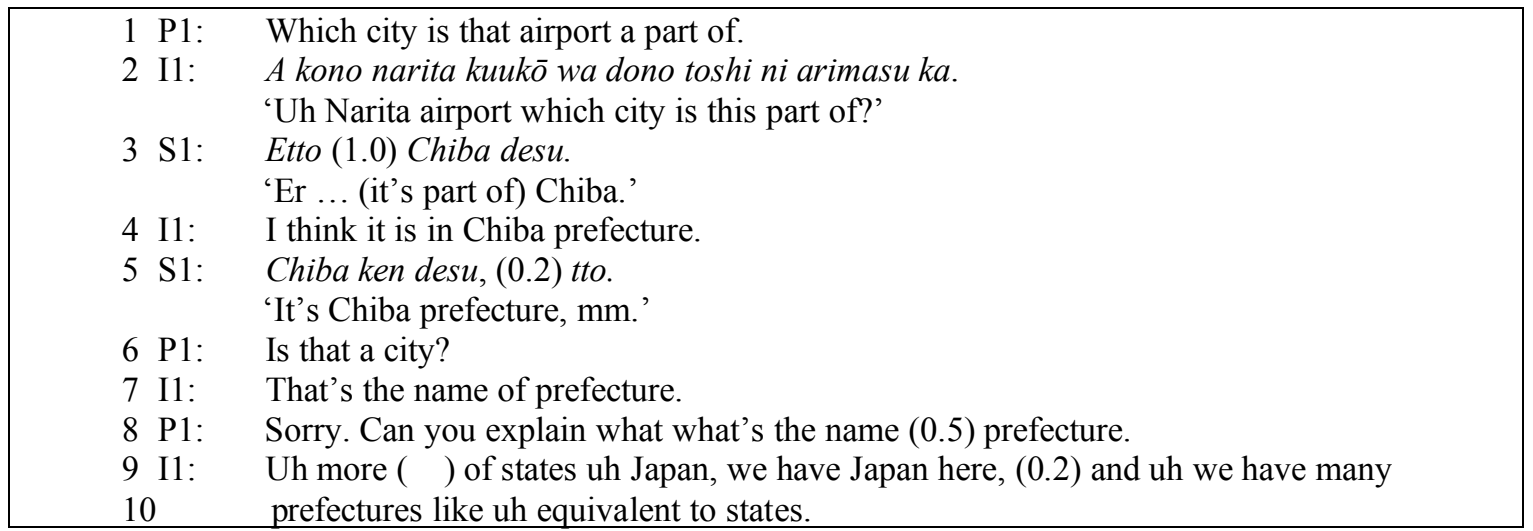
Extract 7.

The police officer is confused because the international airport closest to Tokyo is actually not in the capital but in Chiba prefecture. In this case, the suspect is simply giving a correct answer to the question, and all that the police officer needs is the contextual information from someone with local knowledge. Thus, although the 'I' in line 4 appears to be part of a rendition of the suspect's response in line 3 , the police officer in line 6 asks a question about the place name 'Chiba' without waiting till the interpreter renders line 5 into English. Unfortunately the videorecording is not available to the author, but it is possible that the interpreter thought that the police officer was asking her as a third party if the police officer's non-verbal communication indicated he was talking to the interpreter, especially since he ignored the suspect's elaborated response in line 5. Thus, the interpreter responds directly in English in line 7. At this point, the role shifted from that of animator to principal — in this case, as a kind of cultural informant. The police officer initiates a repair in line 8 and the interpreter responds, again directly in English. It should be noted, however, that the interpreter could have gone further, explaining that Narita airport is the international airport for Tokyo.

In the next extract, the interpreter shifts from animator to author and then to principal. In line 2 , he renders the police officer's question as an animator, although the past perfect 'had' is not rendered accurately and the agent for the verb 'pay' is not specified. The suspect's response in line 3 also does not specify the agent. Agency is further obscured by the use of the passive voice. Prior to the exchanges below, lengthy questioning by the police had taken place without getting accurate information as to who paid how much for what part of the travel by the suspect and his girlfriend. The suspect is apparently reluctant to disclose details of the payment arrangements. This 
affected the interpreter who departed from his animator role to become author/principal in line 4, when he renders a modified question without translating the suspect's evasive response in line 3 . The suspect asks for clarification in line 5 , which by this time appears to be a strategy to buy time, and even after the repair is completed in line 6 , he evades disclosing who paid the airfare. In line 9, the interpreter resumes his role as an animator, faithfully rendering the suspect's response. However, this is followed by a pause of 1.2 seconds, which suggests the police are confused or not satisfied with the information. Taking up this signal, the interpreter then moves from animator to principal role- he explains, as someone who knows the differences between Japanese and English grammars, why the suspect has managed to respond without disclosing the name of the person who paid for the ticket. His role shift is clearly indicated by the use of the third person pronoun 'he' in line 15.

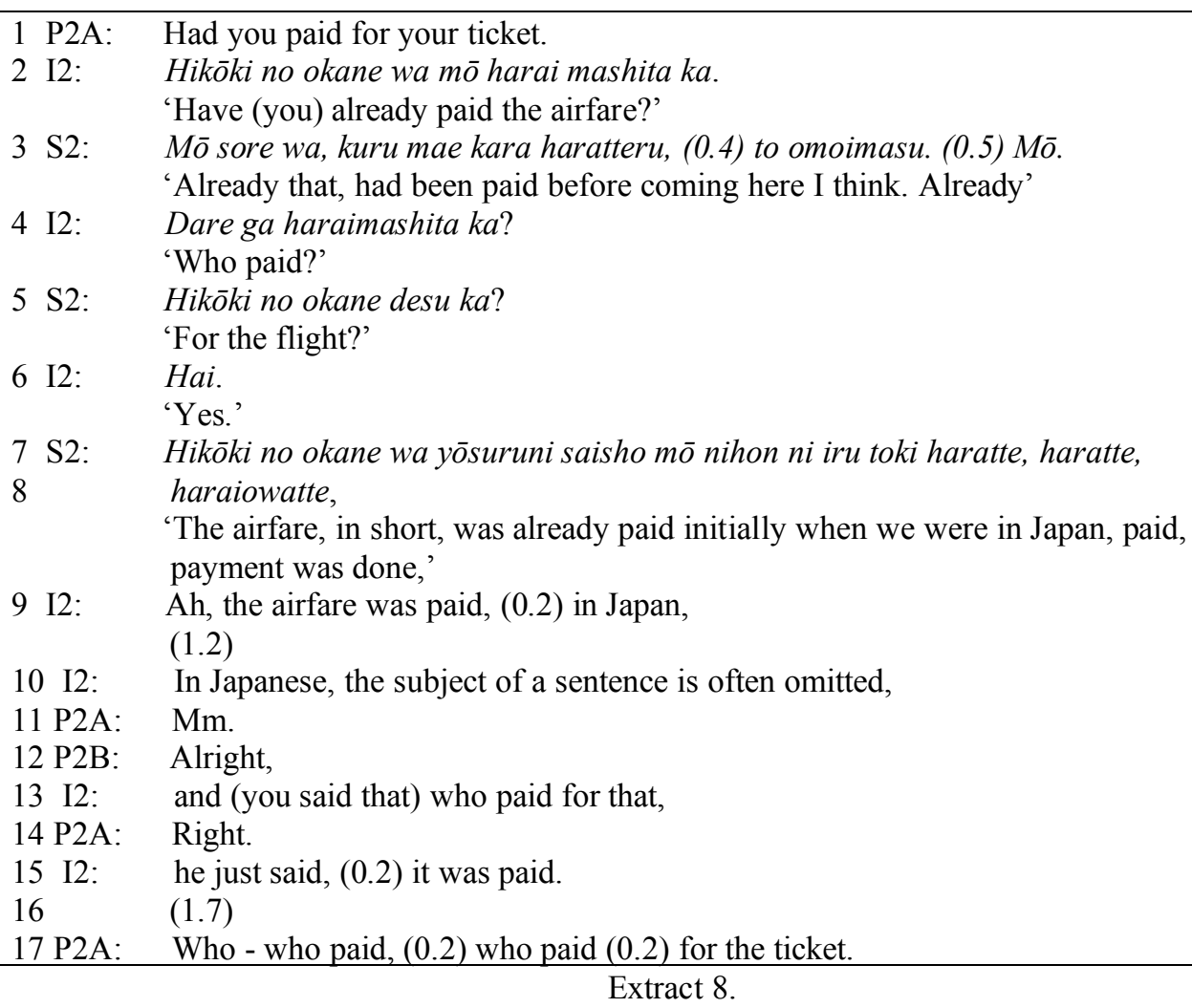

It is apparent that the interpreters in the two examples above cease, at one point, to speak on behalf of the primary speakers and attempt to solve a communication problem as a third party in the interaction. These examples suggest that, as the only person in the interaction who has access to two sets of linguistic and cultural knowledge, interpreters sometimes take a principal role to actively engage in solving problems in police interviews. Similar problem-solving actions by the interpreter have been reported in 
other languages such as Russian-Swedish (Wadensjö 1998: 168-69) and SpanishEnglish (Berk-Seligson 1990: 70). For example, in her study of Spanish-English interpreting, Berk-Seligson (1990: 70) shows examples of court interpreters explaining how witness utterances were translated in order to inform the judges what caused communication problems, a very similar example to the one given in excerpt 8 above. A problem-solving act may be initiated by the primary speaker, as in the case of the police officer in extract 7, or by the interpreters themselves as in extract 8 above. In the latter case, the interpreter's explanation for the suspect's incoherent response not only remedies threatened interactional alignment but also removes doubts that the interpreter's lack of ability brought about the problem. Thus, the interpreter also maintains their reputation as a competent interpreter (Jacobsen 2008: 147).

\section{Summary and conclusion}

The analysis of interpreter-mediated police interviews above has suggested that interpreters at times may diverge from their assumed animator role when problems arise or are anticipated. Such role shifts may be motivated by a number of factors: maintaining interactional alignment; ensuring better intercultural communication; maintaining a competent image; and attending instinctively to the immediately preceding turn. These findings, however, are based on a small sample, and therefore they need to be verified by analysing interpreted police interviews across languages and with a larger number of interviews and interpreters. Nevertheless a small number of studies in other languages - Swedish and Russian (Wadensjo 1998); Spanish and English (Berk-Seligon 1990) — have shown similar examples of role shift occurring in interpreting in legal contexts.

Interpreter role shifts may sometimes be justifiable but at other times problematic: justifiable, when only the interpreter can intervene to avoid miscommunication due to different cultural assumptions; problematic, and possibly unethical, when initiating a repair of their own accord to elicit coherent or preferred responses from the suspect. If information provided by the suspect is not rendered to the police officer, or is unethically elicited at the initiative of the interpreter who fails to remain impartial, important evidence submitted to court is tampered with. Thus, interpreters' mismanagement of repair sequences could have serious consequences when the record of interview goes to court. This also points to the importance of treating records of 
interpreter-mediated police interviews carefully as evidence when the case does go to court. Indeed, the three suspects in this interview data who were found guilty in court claimed that the interpreting service they received was not up to standard. (Melbourne Case Attorneys 2001: 54-55)

The analysis has also shown examples of how complex and difficult it may be for interpreters to maintain their animator role, rendering all that is said accurately and avoiding making inferences of their own accord, within the realities of police interpreting. The study also suggested that such complexity and difficulty may become salient, especially when interpreters are involved in interactions in which problems are perceived. Nevertheless, it appears that interpreters need to be made aware of the contested stakes of the police officer and the suspect in these particular contexts. Conflicts are naturally expected in police interviews and suspects may deliberately use delaying tactics or evasive responses (Newbury \& Johnson 2006: 231; Forrester \& Ramsden 2001: 290-91). Similarly, police officers are aware of the importance of obtaining unsolicited confession that becomes strong evidence in court (Shuy 1998: 174; Heydon 2005: 58), and are trained to interview suspects strategically so they may use questioning strategies that confuse the suspects (Shuy 1998: 14-15; Gibbons 2003: 101). At the same time, police investigators also need to be made aware of the potential risks, particularly in interpreter-mediated interviews, in handling problems in communication with suspects. Finally, the study supported the idea that interpreters are more than 'sound boxes' or 'conduits' and cannot be regarded simply as invisible.

Professionals who work with interpreters in institutional contexts should be made aware that the idea of an 'invisible interpreter' is a myth.

\begin{tabular}{|ll|} 
Appendix & \\
\hline $\mathrm{P} 1,2 \ldots$ & Police officer identification \\
$\mathrm{I} 1,2 \ldots$ & Interpreter identification \\
$\mathrm{S} 1,2 \ldots$ & Suspect identification \\
Italics & Utterances in Japanese \\
$(($ Words in double brackets $))$ & Back translation of Japanese utterances \\
$(0.2)$ & Length of pause \\
, & Continuing intonation contour \\
. & Falling intonation contour \\
$?$ & Rising intonation contour \\
$($ ) & Inaudible utterances \\
{[} & Overlap onset \\
] & Overlap ending \\
$:$ & Lengthened sound \\
$=$ & Latching (no gap) \\
\hline
\end{tabular}




\section{Reference List}

Angelelli, C. 2004, Revisiting the Interpreter's Role: A Study of Conference, Court, and Medical Interpreters in Canada, Mexico and United States, John Benjamins, Amsterdam.

Angermayer, P. S. 2005, 'Who is "You?": Polite Forms of Address and Ambiguous Participant Roles in Court Interpreting,' Target, vol. 17, no. 2, 203-26.

Berk-Seligson, S. 1990, The Bilingual Courtroom: Court Interpreters in the Judicial Process, University of Chicago Press, Chicago.

Berk-Seligson, S. 2002, 'The Miranda Warnings and Linguistic Coercion: The Role of Footing in the Interrogation of a Limited-English Speaking Murder Suspect,' in Language in the Legal Process,' (ed.) J. Cotterill, Palgrave, New York. 127-43.

Eades, D. 1996, 'Legal Recognition of Cultural Differences in Communication: The Case of Robyn Kina,' Language and Communication, vol. 16, no. 3, 215-27.

Forrester, M. A., \& Ramsden, C. A. H. 2001, 'Discursive Ethnomethodology: Analysing Power and Resistance in Talk,' Psychology, Crime \& Law, no. 6, 281-304.

Gibbons, J. 2003, Forensic Linguistics: An Introduction to Language in the Justice System, Oxford, Blackwell.

Goffman, E. 1981, Forms of Talk, University of Pennsylvania Press, Philadelphia.

Hale, S. 2004, The Discourse of Court Interpreting, John Benjamins, Amsterdam.

Heydon, G. 2005, The Language of Police Interviewing, Palgrave Macmillan, Houndmills.

Hyland, T. 2008, 'The Ballad of Chika Honda,' The Sunday Age, 10 February, 13.

Jacobsen, B. 2008, 'Interactional Pragmatics and Court Interpreting: An Analysis of Face,' Interpreting, vol. 10, no. $1,128-58$.

Kurzon, D. 1995, 'The Right of Silence: A Socio-pragmatic Model of Interpretation,' Journal of Pragmatics 23, 55-69.

Laster, K., \& Taylor, V. L. 1994, Interpreters and the Legal System, The Federation Press, Sydney.

Leung, E. S. M. \& Gibbons, J. 2008, 'Who is Responsible?: Participant Roles in Legal Interpreting Cases,' Multilingua, vol. 27, 177-91.

Levinson, S. C. 1983, Pragmatics, Cambridge University Press, Cambridge.

Melbourne Case Attorneys. 2001, Melbourne Case: The Individual Communications. Melbourne Case Attorneys Team, Osaka, Japan.

NAATI Official Website. N.d., 'Accreditation Standards for Translators and Interpreters in Australia.' Online, available: http://www.naati.com.au/at-accreditation.html (Accessed 1 December 2008).

Nakane, I. 2007, 'Communicating the Suspect's Rights: Problems in Interpreting the Caution in Police Interviews,' Applied Linguistics, vol. 28, no. 1, 87-112.

Newbury, P., \& Johnson, A. 2006, 'Suspects' Resistance to Constraining and Coercive Questioning Strategies in the Police Interview,' The International Journal of Speech, Language and the Law, vol. 13, no. 2, 213-40.

Petite, C. 2005, 'Evidence of Repair Mechanisms in Simultaneous Interpreting: A Corpus-based Analysis,' Interpreting, vol. 7, no. 2, 27-49.

Roy, C. B. 2000, Interpreting as a Discourse Process, Oxford University Press, Oxford.

Russell, S. 2000, "Let Me Put it Simply...": The Case for a Standard Translation of the Police Caution and its Explanation,' Forensic Linguistics, vol. 7, no. 1, 26-48.

Russell, S. 2002, “"Three's a Crowd”: Shifting Dynamics in the Interpreted Interview in Language in the Legal Process, (ed.) J. Cotterill, Palgrave Macmillan, New York, 111-26.

Sacks, H., Schegloff, E. A., \& Jefferson, G. 1974, 'A Simplest Systematics for the Organisation of Turn-taking for Conversation,' Language, vol. 50, no. 4, 696-735.

Schegloff, E. A. 1992, 'Repair After Next Turn: The last Structurally Provided Defense of Intersubjectivity in Conversation,' American Journal of Sociology, vol. 97, no. 5, 1295-345.

Schegloff, E. A., Jefferson, G., \& Sacks, H. 1977, 'The Preference for Self-correction in the Organization of Repair in Conversation,' Language, vol. 53, 361-82.

Shuy, R. 1998, The Language of Confession, Interrogation and Deception, Thousand Oaks, Sage.

Suzuki, M. 2000, 'Mujitsu o habamu gengo, bunka no kabe,' Asahi Newspaper, 8 March, 33.

ten Have, P. 1999, Doing Conversation Analysis: A Practical Guide, Sage, London.

Wadensjo, C. 1998, Interpreting as Interaction, Longman, New York.

Wong, J. 2000, 'Delayed Next Turn Repair Initiation in Native/Non-native Speaker English Conversation,' Applied Linguistics, vol. 21, no. 2, 244-67.

Yoshida, R. 2007, 'Interpreting Court Interaction: Redefining the Role of Court Interpreters,' Tsuuyaku Kenkyu (Interpretation Studies), vol. 7, 19-38.

Unde, Y. 2000. 'Kaigai ryokōchuu ni tōgoku sarete 7 nen,' Sunday Mainichi, 2 January, 184-85. 